\title{
SOBRE EXISTÊNCIA, MORTE E ANTECIPAÇÃO
}

\author{
Écio Elvis Pisseta
}

\begin{abstract}
RESUMO
Nos ocuparemos aqui das compreensões heideggerianas da existência, morte e antecipação. Com isso desenvolveremos a noção de Dasein como ser-no-mundo, cuja essência reside em sua existência. Neste caminho, preocupamo-nos com uma interpretação existencialfilosófica da experiência da morte. Exploramos, dentre outras coisas, a noção de que a experiência da morte possui, existencialmente, um privilégio. Ela é uma possibilidade privilegiada porque somente pode ser experimentada antecipadamente, antes de uma morte de fato, mas como possibilidade, nunca como algo que possa em algum momento ser realizado. Desta forma, em seu modo de ser-para-a-morte, o ser humano libera o horizonte da antecipação e da possibilidade como suas experiências primordiais. No fim de todas as possibilidades, na morte, encontra-se a extrema e intransponível possibilidade que, enquanto ela não é, possibilita todo outro relacionamento em seu caráter possível. Esta antecipação compõe a existência. E, junto com isso, no nada de ser desta experiência, pode-se descortinar aquele modo de ser essencial do ser humano, o poder-ser, como uma tarefa de auto-geração de seu próprio ser.
\end{abstract}

PALAVRAS-CHAVE: Existência. Morte. Antecipação. Possibilidade. Heidegger.

\footnotetext{
* Doutor em Filosofia pela Universidade Federal do Rio de Janeiro. E-mail: eciopisetta@yahoo.com.br
} 


\begin{abstract}
We will occupy ourselves with Heidegger's understanding about existence, death and anticipation. So we will develop Dasein concept as being in the world, whose essence localizes in its existence. In this way we will also concern with a philosophical-existential interpretation of death's phenomenon. For instance, we explore the idea that death has, existentially, a privilege. It is a privileged possibility because it can only be experienced beforehand, in advance, and never like something that can, in one moment, be accomplished. So the human being, in his way of being-to-death, frees the horizon of anticipation and possibility as his primordial experiences. At the end of all possibilities, in the death, we find the extreme and insurmountable possibility that, while it is not, permits each relationship in its way of possibility. This anticipation composes the existence. And, joint to this, in the nothing of being of this experience we can discover that essential way of the human being, the power-of-being, like an autogenetic task of his own being.
\end{abstract}

KEYWORDS: Existence. Death. Anticipation. Possibility. Heidegger.

\title{
Introdução
}

Neste texto articularemos três conceitos ou existenciais, característicos da filosofia heideggeriana, desenvolvidos, sobretudo, na obra Ser e tempo: ${ }^{1}$ existência, morte e antecipação. Tanto a escolha destes conceitos, quanto o pano de fundo que justifica sua

${ }^{1}$ HEIDEGGER, Martin. Ser e tempo. Trad. Revisada de Márcia de Sá Cavalcante Schuback. Petrópolis : ed. Vozes; Bragança Paulista : Ed. Universitária São Francisco, 2006, 598p. Esta é nossa principal fonte. Por isso, para simplificarmos, utilizaremos no rodapé a abreviação "ST" para Ser e tempo, seguida do parágrafo e da página correspondente. 
análise, encontra-se na segunda seção de Ser e tempo, entre os $\S 46$ e 53, principalmente, onde Heidegger elabora a construção de um conceito existencial da morte, o ser-para-a-morte.

O ser humano não morre, simplesmente, como outros seres vivos. ${ }^{2}$ A morte sempre está carregada de sentido, revestida das mais estranhas ou evidentes roupagens interpretativas, o que provoca, em geral, muitas confusões. Isto significa que já sempre sabemos algo acerca da morte e que este saber não nos afeta, meramente, a partir do "fato bruto de nossa morte". Desta forma esqueceríamos o mundo circundante fixando-nos, por exemplo, num naturalismo científico acrítico. $^{3}$

Então, como obtemos algum saber sobre ela antecipadamente? $\mathrm{E}$ isto, não simplesmente por meio de comparações, vendo os outros seres vivos morrendo, ou outros seres humanos, para então "antecipadamente" obter algum conhecimento de como é, será ou poderá ser a nossa morte, a dos outros, a morte em geral. Visamos um conhecimento que nos está disponível, principalmente, quando não nos damos conta dele. Nosso conhecimento antecipado da morte revela-a como "possibilidade", mas não como algo que, em algum momento, poderá tornar-se uma realidade. A possibilidade da morte não é nada realizável. ${ }^{4}$ Com estas reflexões almejamos, minimamente, uma compreensão ontológico-existencial, isto é, um entendimento que, tomado pelas exigências de uma interpretação existencial, consiga trazer alguma luz sobre a estrutura ônticoontológica que corresponde ao modo de ser do homem, da presença ${ }^{5}$

${ }^{2}$ Cf. PISETTA, Écio Elvis. Delimitação da análise existencial da morte. In: Revista Educação e Filosofia, v. 20, n. 40, julho-dezembro 2006, p. 81-109.

${ }^{3}$ Cf. ST § 22-24 e HUSSERL, Edmund. A crise da humanidade européia e a filosofia. Porto Alegre : EDIPUCRS, 2002, p.68-69.

${ }^{4}$ Cf. ST $\$ 53$, p. 338.

5 Servimo-nos da tradução brasileira do termo alemão Dasein, "presença”. Por meio da presença procura-se sempre de novo colocar a questão pelo ser do homem e nela permanecer como tarefa intransferível. Por isso, este termo não 
(Dasein). Quando a existência aproxima-se destes limites, seu modo de ser sofre uma transformação especial. Assim aparece o objetivo que justifica este nosso esforço interpretativo: “[...] ao conhecer, a presença adquire um novo estado de ser, no tocante ao mundo já sempre descoberto". ${ }^{6}$ Desta forma, partiremos de uma compreensão da existência para, na seqüência, abrirmos espaço às noções de morte e de antecipação.

\section{A existência}

Heidegger, no $\S 9$ de Ser e tempo, apresenta a essência da presença como sendo a existência (Existenz). Por esse termo distingue-se a essência deste ente da essência dos entes simplesmente dados, compreendidos como meras existências, ou como evidências. Existência não designa uma qüididade, isto é, um modo de ser constante que possa ser determinado categorialmente e que possa ser visto ou comprovado por todos. A existência acena antes para o modo de ser do humano onde ser, existir, é ser e estar inserido na existência ou vida que é cada vez aquela em que estou, a minha. $\mathrm{Na}$ existência, que é minha, transparece a cada vez uma remissão intransferível para o modo de ser do próprio ente privilegiado, que nós sempre somos, que só é ou pode ser, sendo para... outros entes e sendo com... outros seres humanos. Resta sempre como tarefa a compreensão da existência como não sendo de ordem prévia à relação. Em toda relação possível - que é também sempre dotada de sentido - tanto de ordem "material" quanto "imaterial", onde o ser humano está atido a algo, vem a lume nossa condição existencial. Desta forma, a "existência" já sempre se encontra em toda relação

deve ser interpretado como sinônimo de homem ou de ser humano. Investiga-se, na analítica da presença, a dinâmica de constituição de homem e de ser humano. Assim, mesmo no uso que fizermos dos termos "homem" e "ser humano" permanecerá, para nós, ainda em discussão esta dinâmica de constituição.

${ }^{6}$ ST $§ 13$, p. 109. 
possível, antecedendo, por exemplo, toda forma de reflexão ou teoria. Existir nunca sugere simplesmente uma situação mais ou menos "forte" que possa ocorrer na vida de um indivíduo, como, por exemplo, a perda de alguém, ou o nascimento, ou a inquietação do desemprego, da fome, da guerra, etc., em oposição a outras situações não tão decisivas. Existir é a estrutura ou modo de ser essencial e prévio que independe de qualquer valoração porque forja todo valor. Estes ou aqueles valores específicos são acrescentados pelo nosso entendimento a posteriori, a serviço de certos fins universais, querendo reunir e esquematizar certo conjunto de entes num determinado interesse, por exemplo.

Existência - ec-sistência, seguindo a Carta sobre o Humanismo, ${ }^{7}$ significa: $e c=$ fora de, afastado, aberto para... Sugere um estar fora, inserido junto às coisas e convivendo. Mas também sugere a "distância" do afastamento, temporal e espacial, desde onde se pode ver e se pode perceber a distância e a proximidade. Dois "afastamentos": um que remete aos entes intramundanos e aos outros (ao mundo), isto é, separado dos outros, separado das coisas do mundo; outro, que remete à visualização de si mesmo, sendo em conjunto com as coisas e com os outros. Assim, o ser humano não pode ser compreendido como tendo uma existência semelhante à de outros entes. Ele está e existe no mundo, e não pode existir fora dele. Mas ele não está no mundo simplesmente "confundido" com outros seres ou coisas do mundo. Ele está "fora" e esta exterioridade constitui o seu "dentro", a sua "interioridade" ou "primeira identidade"; sistência, in-sistência = alude-se ao modo de ser da presença, do ser humano, que não existe como um vegetal ou animal, mas que insiste em seu modo de ser, isto é, está continuamente aberto para todo ente, sendo com ou lançado para relações sempre diversas que descobrem os entes sob as mais variadas texturas e não pode não descobri-las. A existência constitui-

7 HEIDEGGER, M. Carta sobre o humanismo. In: Conferências e escritos filosóficos. Col. Os Pensadores. São Paulo : Ed. Abril Cultural, 1983, p. 154-155.

Educ. e Filos. Uberlândia, v. 23, n 45, p. 229-258, jan./jun. 2009. 
se por algo a se fazer e não pelo já feito e acabado. Toda constatação de coisas, como aquela de que nascemos num mundo já pronto, tendo que nos adaptar seguindo suas regras pré-estabelecidas, apenas obscurece e desvia nossa compreensão existencial. Mesmo quando nos percebemos em certo modo de existir (escrevendo, cantando, pintando, etc.), nunca somos primeiramente tocados por algo já feito e acabado (como por um "objeto" qualquer), mas antes por uma atividade constituinte de ser, produtora de remissões a outros entes e de camadas de significações. A existência não deve ser confundida com a oposição entre existentia e essentia ou ato e potência. Conforme Ser e tempo: "A substância do homem é a existência". ${ }^{8}$ Trata-se antes de um movimento "produtor" da vida mesma que insiste, que quer ser, a cada vez, autogerando-se. ${ }^{9}$

Como poderíamos explicitar este fenômeno? A existência, esta ou aquela, não se perpetua como o resultado de um processo subjetivo ou industrial de produção, onde a "coisa produzida" expressa a finalização de uma dinâmica de fabricação sempre alheia, em que alguma espécie de "matéria" é transformada até se atingir o acabamento desejado. A existência, tal como a compreendemos, não é gerada por um outro, mas se gera a si mesma. Como? Ela, como a vida, se faz e se desdobra a partir de si mesma, diversificando-se e unificando-se. Ela já sempre foi produtora. É com palavras e gestos que nos assenhoreamos da vida, iniciando algo "imprevisível", algo que não pode ser simplesmente explicado recorrendo-se a alguma causa exterior que, mecanicamente, assumiria todas as responsabilidades pelo resultado. Podemos dizer que fomos, uma primeira vez, jogados biologicamente no mundo quando nascemos, e vivendo, respondemos a esta condição "começando algo novo por nossa própria iniciativa". ${ }^{10}$ É com palavras e atos - com nossa

${ }^{8}$ ST $\S 63$, p. 397. Cf. tb. ST § 43, p. 282 e § 25, p. 173.

${ }^{9} \mathrm{Cf}$. Idem, p. 155. Veja também o caráter de insistência, fundamental à compreensão da existência, na Introdução à metafísica, Rio de Janeiro : ed. Tempo brasileiro, 1969, p. 58.

${ }^{10}$ ARENDT, Hannah. A condição humana. Rio de Janeiro: Forense Universitária, 
ação - que a existência autogera-se, pois esta capacidade depende de nós enquanto presenças. Mesmo uma vida humana alienada não pode ser exclusivamente compreendida a partir de um outro, a partir do controle do processo de produção pelo capitalista, por exemplo. Uma vida alienada possui suas palavras e gestos, sua ação, por meio das quais se gera a si mesma. Posso não concordar com esta vida, mas não posso negar que ela é uma possibilidade de vida humana. Nossa vida é, existencialmente, afirmada e reafirmada, nunca meramente herdada, como a vida animal, que, dentro de certos limites, já nasce "pronta". Nossa existência não se explica simplesmente pela evidência, mas sobretudo como uma tarefa de ser que pertence exclusivamente a nós. Neste sentido, apenas o ser humano existe. Seu ser é sempre ser para fora, lançado junto aos entes intramundanos onde, agindo e falando, constrói infinitas teias de relações.

Quando comparamos o ser humano e o animal percebemos que podemos nos deparar com muitas semelhanças, mas também e sobretudo, com um abismo. Esta distância nunca é meramente espacial, como o afastamento passível de medição entre dois corpos. Ela é principalmente um modo de ser responsável pelo estabelecimento, a cada vez, de proximidades e de afastamentos que não se reduzem às distâncias entre os objetos físicos. O modo de ser do humano habita, em certo sentido, um abismo "irreconciliável" com os demais entes. Esta situação, por um lado, determina toda relação e apreensão dos entes onde o ser humano afirma sua diferença. Mas, por outro, na afirmação desta diferença essencial, ele prova que não pode encontrar sua identidade sem estabelecer alguma forma de relação com os demais entes.

Relacionemos, agora, o que observamos acerca da existência com o ente privilegiado que nós mesmos somos.

1993, p. 190, 348p. 


\section{Presença e circunstância}

Presença, Dasein, segundo a interpretação que lhe dá Heidegger, não se refere à existência do ser humano em sentido tradicional, usada para designar o real e a realidade, nem a posição humana corriqueira de estar aí, ist da. Presença, pre-sens (Da-sein), indica a situação ontológica de ser aqui, ser ali, ser antes, ser sempre, de modo prévio a qualquer determinação possível. A composição desta estrutura constituinte do ser humano nos joga numa possibilidade de compreensão que não pertence nem ao sujeito, nem ao objeto, nem ao espírito, nem à matéria, etc. Podemos ver aqui a conexão primordial entre o "pré", o "da" e o "Ek, ec", com o Sein, o ser. Esta conexão não se dá segundo o modo de uma separação como a de ser e ente, mente e corpo, espírito e matéria, etc., onde se pode fazer alguma interpretação causal, juntando-as. A conexão já sempre aconteceu em cada modo de ser, em cada projeto existencial onde o ser humano se encontra determinado a cada vez desta ou daquela forma, mas nunca como um "voluntarismo". Esta estrutura essencial recebe o nome de "acontecimento". Nela, o ser humano exteriorizase em determinado projeto ou modo de ser. Sendo a cada vez num mundo de realizações determinadas, o ser humano existe. Não é o homem que, simplesmente, toma a iniciativa nesta empreitada. Ele próprio é, de certa forma, produto, resultado tardio, fruto do acontecimento no acontecimento. Assim, a existência humana não pode ser pensada como algo pronto e acabado, mas como estando destinada a acabamentos. E, principalmente, a existência humana não pode ser pensada como desvinculada de suas exteriorizações. A estrutura prévia de que falamos mantém numa unidade o modo de ser humano e o mundo de suas efetivações, diferenciando, ao mesmo tempo, cada exteriorização de fato, do próprio modo de ser que pertence ao ser humano. A existência se mostra como uma tarefa infinita de ser. É o que podemos entender quando pensamos não a partir de uma forma histórica já sedimentada de homem e mundo, 
sempre possível, mas a partir da geração de toda forma histórica, a partir da "clareira do ser"."

O ser humano é o único ente que pode ver a si mesmo, isto é, que pode perceber-se, compreender-se, em seus diversos modos de ser. Existir não é ser, em especial, nesta ou naquela experiência, mas "simplesmente" ser, que é ser-em um mundo e nisso, ser numa possibilidade de relação que, por sua vez, pode ser própria ou imprópria (na linguagem de Heidegger). Esta situação de existir, como uma tarefa intransferível onde a vida mesma está em perigo aparece, por exemplo, na citação de Ortega y Gasset, em seu livro, $O$ homem e a gente:

Mas a vida humana é sempre a de cada um, é a vida individual ou pessoal e consiste em que o EU que cada qual é se encontre tendo de existir em uma circunstância, - o que costumamos chamar mundo, - sem segurança de existir no instante imediato, tendo sempre de estar fazendo algo, - material ou mentalmente, - para assegurar essa existência. O conjunto desses afazeres, ações ou comportamentos, é a nossa vida. ${ }^{12}$

Nossa existência não é nada de seguro. Ela não é uma propriedade ou qualidade do ser humano, mas seu modo de ser. Se, por um lado, cada um é e vive sempre sua existência, por outro, ela é o lugar ou a situação onde o ser humano pode, existindo, se achar ou se perder. Quando Heidegger fala de "próprio" e "impróprio", os dois grandes caracteres da existência, co-fala da possibilidade sempre presente do ser humano se ganhar ou se perder, descobrir sua vida a partir de sua constituição fundamental de ser - singular e intransferível - ou de ser levado pela multidão, pelos outros que

\footnotetext{
${ }^{11}$ Cf. HEIDEGGER, M. Carta sobre o humanismo. Op. Cit., p. 161.

${ }^{12}$ ORTEGA Y GASSET, José. O homem e a gente. RJ : Ed. Livro Ibero-americano, 1960, p. 45. Grifo nosso.
} 
podem lhe tomar o ser. Assim, se sou minha existência, se ela é cada vez minha, isto não quer dizer que ela é algo pronto e acabado. Daí a característica, que pertence ao ser humano, de estar continuamente fazendo algo.

Circunstância, no texto aludido, é sempre o derredor, o entorno no qual eu sempre sou e estou, tendo de existir, isto é, ser de alguma maneira. Sou, sendo-para as coisas, num determinado contexto de trabalho, por exemplo, e sendo-com os outros, em alguma forma de convivência. Existo num mundo fazendo algo, isto é, sendo. $\mathrm{O}$ afazer não sugere meramente a possibilidade de se produzir algo, de se fabricar, mas também o contexto de toda e qualquer atividade. Numa caminhada distraída, sou junto com os outros, os transeuntes, e também sou, faço ou descubro um determinado sentido em meu derredor, tanto na conversa ou nos olhares que se cruzam, nas roupas, no calçado, no chão sobre o qual piso, quanto na paisagem que se descortina. Um mundo de possibilidades nasce nesse e desse afazer. O ser humano é ser-no-mundo. Ele não pode não existir. " $A$ 'essência' da presença está em sua existência". ${ }^{13}$

\section{Existência e jogo}

Outra explicitação acerca do ser do homem que aparece em Ser e tempo é: "O ser, que está em jogo no ser deste ente, é sempre meu". ${ }^{14}$ A expressão "que está em jogo", indica a textura da existência: o essencial, o fundamental, o que está em relevo é o modo de ser do homem, um modo que lhe pertence a cada vez e que, igualmente, o transcende. Tanto o pertencimento a cada situação quanto sua superação ou transcendência correspondem ao modo de ser do humano. Na experiência de estar em jogo devemos nos precaver de imaginarmos um ser humano que permaneça o mesmo

\footnotetext{
${ }^{13} \mathrm{ST} \S 9$, p. 85.

${ }^{14}$ ST $\$ 9$, p. 86.

Educ. e Filos. Uberlândia, v. 23, n 45, p. 229-258, jan./jun. 2009. 
em todas as variações possíveis da vida. Estar em jogo a cada vez: não remete a uma experiência descartável. Situado, o ser humano é sempre seu princípio e fim, o ponto de partida e o destino. Lançado, circunscrito, delimitado sempre num aqui e agora, o ser humano é para si mesmo, mesmo que de forma confusa e obscura. "Em seu ser, a presença já sempre se conjugou com uma possibilidade de si mesma". ${ }^{15}$ Pertence-lhe, então, já sempre ser junto com algo. O ser humano não é algo "puro", separado e isolado das contaminações características de seu engajamento numa situação de fato, como se habitasse uma redoma de vidro que o isolasse das coisas mundanas. Está em jogo, então, a cada vez, o ser humano e sua identidade, o ser humano e sua diferença frente a outros entes, os entes em suas mais variadas composições e significações, enfim, o ser em um mundo de cada presença. Em sua situação, sempre localizada, está em jogo o seu ser, pois ele sempre pode ser, em existindo, algo outro do que é.

Podemos acrescentar, seguindo este viés, que quando o ser humano chega para determinado relacionamento, ele já se aproxima carregado de história, de influências, de experiências as mais diversas. O ser humano nunca chega "intacto". Seu ser já sempre se formou, deformou, conformou numa infinidade de relacionamentos que já sempre o perpassaram. Dentre estas experiências encontramse as metafísicas, isto é, certas compreensões universais de mundo e de ser humano, que procuram, de diversas formas, enquadrar ou esquematizar a realidade em conceitos gerais que, por sua vez, servirão como norteadores para ulteriores investigações nos mais diversos campos. Mas estas, as metafísicas, em seu afã de universalidade e de esquematização, fazem calar aquelas, as experiências mais diversas. A uniformidade supera a pluralidade. Salta aos olhos a decisão heideggeriana de não compartilhar com um conceito universal de ser humano, como se ele fosse dotado de um ser a priori, independente dos múltiplos relacionamentos que vão e vêm. O ser humano

${ }^{15} \mathrm{ST} \S 41$, p. 258. 
compromete-se e sempre já se comprometeu, existencialmente, com a busca de sua essência. Esta decisão traz como conseqüência, não compartilhando com um conceito universal e uniforme de homem, o desafio de compreendê-lo a partir das ocupações, preocupações, compromissos que, a todo o momento, constituem a sua vida. A ação ou atividade é o princípio. E o ser humano, de fato, já sempre esteve e está a fazer, a agir neste sentido, quer ele o saiba de maneira explícita ou não.

No entanto, o afazer humano já sempre se contaminou pelo mundo da "gente", de todo mundo, pelo impessoalmente si-mesmo, pelo próprio-impessoal (Man-selbst). ${ }^{16} \mathrm{O}$ ser humano, em geral, está a viver segundo o modo da decadência (das Verfallen), onde já sempre "decaiu de si" junto ao mundo com os outros e com as coisas. Mas isto não equivale a um erro, como se não devesse ser assim, como se existisse um modo de ser livre das influências alheias. A decadência expressa um primeiro e mais comum extrato da existência humana, onde os outros, a princípio, lhe tomam o ser, se responsabilizam pelo seu ser, lhe retiram, das mais diversas formas, a responsabilidade de ter que se haver com seu próprio ser. Não é isso que a tradição metafísica faz? Se ela já pensa pelo ser humano, já diz o que é o real e a realidade, para que ter que se haver com esta tarefa? Assim, a cada vez, está em jogo o modo de ser do humano, o acontecimento de cada homem singular. Ele é sempre e a cada vez meu, mesmo que de modo impróprio, isto é, mesmo que não nos percebamos como estando na tarefa de termos que nos haver com nosso próprio ser.

Está em jogo, na existência, cada ser humano enquanto presença efetiva. Nossa reflexão não deve buscar sob quais modos de ser o ser humano se encontra ou se perde. Com isso elegeríamos uma hierarquia de modos de ser, moralizaríamos a vida. Mas, segundo que critérios? Há muito nos distanciaríamos da análise existencial! O importante é a noção de possibilidade que mantém

$\overline{{ }^{16} \text { Cf. ST } \S 27, \text { p. } 186 .}$

Educ. e Filos. Uberlândia, v. 23, n 45, p. 229-258, jan./jun. 2009. 
como que aberta cada atividade em que o ser humano está. De modo simples, o que isto significa? $\mathrm{O}$ modo de ser atividade não se caracteriza, meramente, pela existência de um "movimento" em oposição a uma "fixidez". Estes conceitos podem ser aplicados a atividades específicas, mas não ao modo de ser de toda atividade, pois a partir daquelas se compreende que uma atividade tende, em algum momento, à sua cessação. Mas, a partir do modo de ser da atividade pode-se entender que um comportamento "quieto" detenha alguma forma de movimento. Neste sentido pertence à atividade um existencial denominado "possibilidade". Em toda ação vem à tona a lembrança da alteridade, de cada atividade poder ser outra. Em fazendo seja o que for, o ser humano está remetido a algo, aberto para um mundo de possibilidades. Segundo uma compreensão existencial, a possibilidade não se opõe à realidade. Isto significa que o entendimento de toda atividade, sua compreensão e sentido, não deve ser buscado no já feito e acabado, mas no devir, no a-ser-feito. Talvez a noção de possibilidade nos ensine que não há, existencialmente, um ente pronto e acabado para todo o sempre. Se houvesse, ele estaria destituído de toda remissão e, conseqüentemente, não poderia ser interpretado. A atividade, enquanto correlata à de existência, permanece irmã da surpresa, do espanto, do inesperado, do possível. Em seu poder-ser para possibilidades, e não simplesmente para esta ou aquela efetivação, o ser humano já sempre está no perigo de se encontrar e de se perder, pois sua existência não se constitui como algo decidido para todo o sempre. E o ser humano, de fato, nunca se achou completamente, devendo sempre se retomar, nem se perdeu inteiramente, podendo sempre se encontrar.

Mas, como podemos esclarecer esta compreensão existencial da presença como "poder-ser" para possibilidades? Encontramos um caminho nos desdobramentos que Heidegger dá ao existencial denominado ser-para-a-morte. Vejamos alguns pontos. 


\section{O ser-para-a-morte}

O ser humano não morre como os outros seres vivos. A morte sempre o afeta antecipadamente. Isto não significa que o ser humano detenha um conhecimento objetivo sobre a efetividade de sua morte, de tal forma que possa orientar os seus passos em relação a ela, para dela esquivar-se, por exemplo. A bem dizer, com ela o ser humano nada pode fazer. Assim, não nos interessa o estudo de casos de morte, nem de como coletivamente o ser humano se comporta com a morte, nem de sua possível função como uma passagem para um "além" da vida. Interessa-nos percebê-la como estando continuamente presente na vida humana fornecendo-nos uma compreensão da existência.

A experiência da morte possui, existencialmente, um privilégio. Enquanto eu sou, tudo pode ser; quando eu não mais existir, nada mais será. Ela é a "possibilidade da impossibilidade da existência". ${ }^{17}$ No entanto, tamanha impossibilidade é apenas experimentada antecipadamente, de tal forma que a experiência da morte libera o entendimento humano para a percepção dessa possibilidade, que não encontra parâmetro em nenhuma realidade possível. Pois se de fato morro, como posso deter algum saber de minha intransferível morte? Por isso, esta experiência dá-se como uma "compreensão" incomum. A textura, o terror, a seriedade desta compreensão, independe de toda efetivação e de toda "experiência psicológica", detendo uma autonomia ontológica que se traduz como possibilidade. Nunca como algo que possa em algum momento ser realizado. Desta forma, em seu modo de ser-para-amorte, o ser humano libera para seu entendimento os horizontes da antecipação e da possibilidade como experiências primordiais de seu ser. Antecipação e possibilidade adquirem um sentido existencial, não acopladas às noções mais diversas de realidade e de planejamento, podendo ser pensadas sem nenhuma vinculação

\footnotetext{
${ }^{17}$ ST §53, p. 339. 
necessária ao âmbito da realidade. Antecipadamente sei da minha morte como possibilidade. No fim, que é o fim possível de todas as possibilidades realizáveis, isto é, na morte, encontra-se a extrema e intransponível possibilidade. Enquanto ela não é, possibilita todo outro relacionamento permitindo, assim, a descoberta destes relacionamentos como possibilidades existenciais. Mas não é assim que pensamos cotidianamente. Consideramos boa parte de nossas realizações científicas, sócio-culturais, políticas, etc., como eternas e imutáveis. Pensemos no sistema heliocêntrico, em nossa língua pátria, na organização política dividida em poderes independentes, na compreensão do ser humano como um ser vivo semelhante a outros seres, etc. Se, em geral, tendemos a conferir às mais diversas efetivações o caráter de realidade, de eternidade, de permanência, etc., a experiência antecipada da possibilidade da morte "relativiza" e confere um "novo sentido" a tudo isso. E, mais radicalmente, no nada de ser desta experiência pode-se descortinar aquele modo de ser essencial do humano, o poder-ser, como uma tarefa de autogeração de seu próprio ser. Pois é, em sendo, que somos, e que cada coisa igualmente encontra seu ser.

O ser-para-a-morte traz para o pensamento a provocação essencial de que o ser humano, a cada momento, é ser-para-o-fim. Este ser-para é visado na problemática existencial desdobrada em Ser e tempo. No $\S 52$ encontramos sua formulação existencial: "Enquanto fim da presença, a morte é a possibilidade mais própria, irremissivel, certa e, como tal, indeterminada e insuperável da presença. Enquanto fim da presença, a morte é e está em seu serpara o fim". ${ }^{18}$

A morte é a possibilidade mais própria..., chamando o ser humano a si. Ninguém pode morrer a morte de outro. A compreensão deste modo de ser próprio revela ao ser humano que ele, geralmente, está perdido no impessoal, submetido a um agir, a um pensar, a um

${ }^{18} \mathrm{ST} \S 52$, p. 335. 
“ser", que é comum a todos. É também irremissivel, reivindicando para o ser humano sua singularidade, lembrando-o constantemente que, mesmo envolvido com os outros e as coisas que ele não é, está projetado para uma compreensão transcendente de si mesmo. Os outros e as coisas perfazem a determinação ontológico-existencial conhecida por impessoal, como o ser humano é antes de tudo e na maioria das vezes. Ocorre que ele não precisa ser sempre e exclusivamente a partir desta orientação impessoal de ser. Ele pode a cada vez escolher, sendo para possibilidades. A possibilidade da morte é, também, insuperável. Antecipar a possibilidade da morte não é "sobrepujar" a insuperabilidade da morte, mas liberar a compreensão humana para este horizonte. Assim, sendo a partir dos limites liberados a partir do fim, o ser humano pode evitar perder-se nas possibilidades ocasionais tomando-as como permanentes, eternas, imóveis.

O antecipar abre para a existência como possibilidade mais extrema a tarefa de sua propriedade, rompendo assim todo e qualquer enrijecimento da existência já alcançada. Antecipando, a presença evita recuar para trás de si mesma e da compreensão de seu poder-ser, evitando 'tornar-se velha demais para as suas vitórias' (Nietzsche). ${ }^{19}$

A mesma existência em que sempre habitamos já não é mais a "mesma". Ela toda se modificou. A mudança encontra-se na aquisição de uma nova compreensão, distinta de qualquer acréscimo ou adição a uma compreensão já existente. Trata-se, antes, de uma transformação de nossa vida ou de nosso modo de compreender a vida. É no toque ou na força desta antecipação da possibilidade extrema que, segundo Nietzsche, o ser humano encontra a sua jovialidade, o seu nascimento existencial, "começando algo novo por sua própria iniciativa".

\footnotetext{
${ }^{19} \mathrm{ST} \S 53$, p. 341. 
$\mathrm{Na}$ antecipação da possibilidade insuperável reside a chance de tomar e compreender o ser humano em sua totalidade como "poder-ser". ${ }^{20}$ Esta compreensão de totalidade diz respeito ao caráter de abertura de seu poder-ser num mundo e para um mundo de possibilidades e não a uma soma de partes. $\mathrm{O}$ entendimento desta possibilidade surge como uma tarefa de construção ou apropriação de seu próprio ser em cada atividade prática ou teórica em que ele se encontre. Fazendo, seja o que for, o ser humano percebe que sua vida está atada a uma "fabricação" (em sentido amplo) do mundo e de si mesmo. No entanto, não nos referimos a uma atividade puramente automática, embora seja a mais freqüente. Este poder-ser visado descortinou-se para nossa compreensão a partir da antecipação da possibilidade extrema. Desta forma, antecipadamente, cada atividade já está contaminada pelo modo de ser da propriedade. Todas as atividades possíveis nascem da antecipação da possibilidade extrema, não sendo nunca meramente herdadas.

Acrescentemos, ainda, que a possibilidade da morte é certa, certeza que não se confunde com uma evidência acerca dos outros entes nem com a certeza corriqueira da morte de alguém. A verdade da morte e sua certeza, no sentido aludido, não podem ser provadas segundo os modos e métodos lógicos, por exemplo. Esta certeza é também indeterminada, isto é, possível a todo o momento. A certeza indeterminada da morte coloca o ser humano diante de uma ameaça que não pode ser apagada. Esta traz à tona um afeto experimentado como "insuportável”, mas que remete à constituição mais própria do ser humano. Trata-se da angústia, gêmea da morte, que não pode ser confundida com algum sentimento corriqueiro. Ela mantém aberta uma ameaça absoluta e insistente. "Na angústia, a presença se dispõe frente ao nada da possível impossibilidade de sua existência". ${ }^{21}$

Mortal e angustiado, o ser humano vive a possibilidade de

\footnotetext{
${ }^{20} \mathrm{ST} \S 53$, p. 341.

${ }^{21} \mathrm{ST} \S 53$, p. 343.
}

Educ. e Filos. Uberlândia, v. 23, n 45, p. 229-258, jan./jun. 2009. 
não-ser, sendo. Ele se angustia com e a partir de seu próprio caráter de possibilidade. A força da possibilidade despertou por meio da experiência da morte. A existência, atravessada pela antecipação da possibilidade da morte, se defronta com seu jeito próprio de ser, ser prévio, onde está em jogo todo o seu ser. A angústia libera a possibilidade do ser humano compreender-se como unidade nas possibilidades mais diversas. Uma angústia frente a nada de fato, isto é, frente ao si mesmo humano que pode ser interpretado como um nada. A este "nada de si" aludem diretamente os existenciais da antecipação e da possibilidade. E devido ao seu caráter propiciador de aberturas, podemos dizer que o ser humano, em seu poder-ser, é "liberdade para a morte" 22 e que, desembaraçando-se das ilusões do impessoal, se angustia.

Todos os fenômenos apresentados interpretam a singularidade da morte humana. Apenas uma abordagem existencial, segundo Heidegger, é capaz de pensar a morte incluída na existência. Dissemos que, existencialmente, a "presença" habita a antecipação. No entanto, como foi que se nos delineou esta estrutura da anterioridade? De maneira especial a partir da abordagem do ser-para-a-morte. " Serpara-a-morte é antecipar o poder-ser de um ente cujo modo de ser é, em si mesmo, o antecipar". ${ }^{23} \mathrm{Na}$ antecipação reside a memória de um modo de ser fundamental. Em sendo, cada vez, já sou previamente como possibilidade de ser para algo.

\section{Existência e poder-ser}

A experiência radical da angústia e da morte favorece um "entendimento" a partir do qual o ser humano pode interpretar suas ações e preocupações como possibilidades antecipadas e não como realidades cristalizadas. Pode também interpretar a propriedade e

\footnotetext{
${ }^{22} \mathrm{ST} \S 53$, p. 343.

${ }^{23} \mathrm{ST} \S 53$, p.339. 
a impropriedade como possibilidades da existência. Aceitar uma determinada forma da realidade (uma sua aparência históricosocial, por exemplo) como sendo a única expressão da existência é compreendê-la impropriamente. Neste sentido, a existência seria apresentada como já sedimentada e não nascida a partir da vida mesma, "informe" criadora de formas. Por outro lado, tomar a vida como possibilidade de ser, presente na necessidade de sempre estar a fazer, é aquiescer ao que pode ser como decisivo e, portanto, como algo que nasce da própria vida em se fazendo. Este modo de entender a vida contrapõe-se, até certo ponto, ao anterior. Propriedade e impropriedade opõem-se naquilo que cada uma toma como orientação fundamental, ora uma forma de vida já petrificada, ora a dinâmica produtora da vida. A "propriedade" não nasce da compreensão da existência como algo já construído, mas como algo a se fazer. A ação ou atividade ocupa um lugar - ontológico - prévio a toda determinação. Neste âmbito acontece a vida, na qual o tempo, a existência, a morte, a decisão, etc., se encontram num único lance, pois em cada atividade ganha forma o próprio poder-ser. Como elucidar, por ora, este poder-ser? Vejamos um pequeno trecho de Ortega y Gasset, retirado do livro A rebelião das massas:

[...] nossa vida é em todo instante e antes que nada, consciência do que nos é possível. Se em cada momento não tivéssemos à nossa frente mais que uma só possibilidade, careceria de sentido chamá-la assim. Seria apenas pura necessidade. Mas aí está: esse estranhíssimo fato de nossa vida possui a condição radical de que sempre encontra ante si várias saídas, que por serem várias adquirem o caráter de possibilidades entre as quais havemos de decidir. Tanto vale dizer que vivemos como dizer que nos encontramos em um ambiente de possibilidades determinadas. A este âmbito costuma chamar-se "as circunstâncias". Toda vida é achar-se dentro da "circunstância" ou mundo. Porque este é o sentido originário da idéia (mundo). Mundo é o repertório de nossas possibilidades vitais.

Educ. e Filos. Uberlândia, v. 23, n 45, p. 229-258, jan./jun. 2009. 
[...] Representa o que podemos ser; portanto, nossa potencialidade vital. Esta tem de se concretizar para realizar-se, ou, dito de outra maneira, chegamos a ser só uma parte mínima do que podemos ser. Daí que nos parece o mundo uma coisa tão enorme, e nós, dentro dele, uma coisa tão pequena. ${ }^{24}$

Mundo ou circunstância, é o repertório de nossas possibilidades vitais. Alude-se à noção de possibilidade, mas não no sentido de uma absolutização do devir contra toda estabilidade. Não se está dizendo que o realíssimo é o puro e constante fluxo. Como se poria mãos à obra? Careceríamos da matéria imediata, fática, em que já nos encontramos e a partir da qual "descobrimos" o devir. O possível se revela a partir de uma situação em que sempre já nos encontramos. Dessa forma, a citação acima remete a uma compreensão deste mundo liberado, a cada vez, como uma pluralidade de caminhos. "Esse campo deveniente é precisamente o mundo circundante como o espaço existenciário de realização da vida impessoal cotidiana [...]". ${ }^{25} \mathrm{O}$ poder-ser num mundo aberto nos lembra incessantemente de que somos mais, de que o possível é a maior parte de nossa vida, de que nossa potencialidade vital se apresenta como sendo o possível de toda efetividade, como sendo o não-ser de todo ser. Nos expressamos desta forma para não procurarmos um poder-ser como se estivéssemos à caça de uma "essência", ou de um lugar, como uma última causa, ou um ponto extremo de uma série. É na própria constituição da existência, em seu "jeito" sempre insistente de atarefar-se, que podemos encontrar este modo de ser. Poder-ser é sempre poder-ser para algo e (ou) com algo ou junto com algo. Encontramos uma situação que deve ser concebida como dinamicamente aberta, à medida que este "poder" realiza-se

${ }^{24}$ ORTEGA Y GASSET, José. A rebelião das massas. Rio de Janeiro: ed. Livro Ibero-americano ltda, 1962, p. 93-94. Grifo nosso.

${ }^{25}$ CASANOVA, Marco Antônio. Nada a caminho. Impessoalidade, niilismo e técnica na obra de Martin Heidegger. Rio de Janeiro: Forense Universitária, 2006, p. 6, 194p. 
naquilo que está em andamento, à medida que é somente para aquilo que se fará, como uma vontade carente de ser. Este poder leva, de certa forma, tudo o que há, para o possível, para a sua "essência existencial", para o seu lugar de nascimento, seu "elemento". ${ }^{26}$ Mas este poder também traz todo o possível para uma situação finita, para a um jogo de relações, a cada vez, fechado em si mesmo.

Todavia, se é um poder fechado em si mesmo, como está presente a possibilidade de ser outro, de haver uma outra efetividade? Quando interpretamos este aspecto de fechamento como uma unidade auto-suficiente que dispensaria toda alteridade, recairíamos numa compreensão substancialista da existência. Nos colocaríamos fora da situação, entendendo uma atividade como "fechada em si mesma". No entanto, devemos considerar que o fechamento aludido remete sempre a um engajamento determinado. Diz respeito à sua autonomia de ser, à unidade circular do mundo circundante, que se compreende a partir de seu próprio movimento de ser. É jogando, isto é, sendo, que se participa do jogo. Está-se inserido em determinada atividade, isto é, disponível à sua dinâmica, sua potencialidade vital, e podendo, também, a cada momento, encontrar-se ou perceber-se noutra dinâmica de ser. Isto significa que sempre estamos engajados em atividades que são abertas e fechadas simultaneamente, e não ora abertas ora fechadas. As possibilidades liberadas não estão meramente em nosso poder subjetivo. Não é o "eu" ou o "cogito" ou "a razão" que determina e orienta este processo. Ele acontece. Ele dá-se. Ele forja a existência a cada vez. Quando compreendemos a experiência da morte em seu caráter privilegiado e estranhíssimo encontramos as experiências de "abertura" e de "fechamento" que não admitem, nenhum artificialismo. Não seria então sem sentido a noção ontológica de que fechamento $e ́$ abertura e abertura é fechamento. A existência não foi também assim expressa há pouco? E este poder-ser, não é aquilo "pelo que" e "diante

${ }^{26}$ Cf. HEIDEGGER, M. Carta sobre o humanismo. Op. Cit., p. 150. "O elemento é o que propriamente pode: o poder (das Vermögen). Ele assume o pensar e o conduz, assim, para sua essência".

Educ. e Filos. Uberlândia, v. 23, n 45, p. 229-258, jan./jun. 2009 
do que" a angústia se angustia? Expressamos, citando Heidegger, o modo da compreensão assimilar ou incorporar esta experiência "como o poder-ser capaz de propiciar aberturas". ${ }^{27}$

Como ser livre para o poder-ser mais próprio? De certa forma, não nos deixando levar pelas possibilidades ocasionais ou corriqueiras em que sempre já estamos. Não que possamos, em algum momento, não estar mais atidos a estas. No entanto, como seres pensantes que somos, podemos sempre sobrecarregar estas situações, tomando-as como realidades em si e não como possibilidades. Se não nos concentramos em nosso agir, que é tanto lidar com as mãos quanto refletir, mas nas efetividades ou realidades, então tomaremos estas experiências não mais como possibilidades. Não estaremos mais livres para o poder-ser, porque cairemos na tentação da "forma", do que é duradouro e que não quer morrer. Esta possibilidade de não atender mais ao seu poder-ser mais próprio pertence também ao próprio poder-ser. Porque a presença é sempre e continuamente para possibilidades é que ela pode, em algum momento ou continuamente, deixar-se compreender e orientar por uma possibilidade, instaurando-a como uma espécie de fundamento.

Ser livre para o poder-ser mais próprio, no entanto, inclui em si esta disponibilidade para a morte, existencialmente compreendida. A partir da disposição da angústia, o ser humano angustia-se com aquele modo de ser fundamental que não depende de nenhum outro e do qual dependem, para ser, todas as outras possibilidades. Esta experiência já sempre lhe pertenceu como um modo "de ser livre para o poder-ser mais próprio". O modo de ser livre que nasce a partir deste poder-ser remete sempre às múltiplas compreensões, interpretações, "saídas", que já estão antecipadamente liberadas em cada atividade determinada. Mas, como interpretar esta "compreensão" que não é da ordem de uma objetividade ou subjetividade, de uma essência ou substância, mas de abertura, de uma indeterminação essencial?

\footnotetext{
${ }^{27} \mathrm{ST} \S 31$, p. 204. 


\section{Poder-ser e antecipação}

Sendo a cada vez segundo um modo de ser sempre determinado, o ser humano já sempre pôs em jogo o seu ser. Demonstra, assim, uma forma singular de compreensão de si mesmo: ele, em se projetando a cada vez desta ou daquela maneira, não se fixa nesta ou naquela determinação, mas sim para o que está em jogo a cada vez, seu poder-ser mais próprio, seu modo de ser como dinâmica de autoconstituição. Nesta decisão manifesta-se o fenômeno da temporalidade a partir do qual o projeto existencial é forjado, isto é, uma compreensão de tempo a partir do "futuro". Mas por que falamos disto? A antecipação, ela mesma, tornou-se visível em seu sentido a partir do ser-para-a-morte.

No poder-ser, enquanto abertura, já sempre reside uma compreensão. "Compreender é o ser desse poder-ser" ${ }^{28}$ que pertence a cada vez ao modo de ser do homem de modo mais ou menos transparente. Este poder-ser só pode agir, desta ou daquela maneira, porque já sempre soube como fazê-lo. Enquanto existência, o ser humano é também compreensão de si, do mundo, das coisas, do ser, do que sabe e do que não-sabe. Sendo, o ser humano é (e sempre já foi) numa possibilidade de si mesmo, já sabendo "de si" e do "mundo", já sabendo "pegar" as coisas, avaliar, antever, prever e orientar seus gestos. Errar, confundir-se, prejudicar-se, desdenhar, ignorar, etc., devem ser vistos como modos de compreender e de orientar a vida, isto é, de ser-no-mundo. O atamento existencial do ser humano a toda ocupação e preocupação revela uma compreensão primária, de ordem não-reflexiva. Ela é "prática", isto é, atida ao mundo e ativa, dada e doada por nenhuma subjetividade ou objetividade. O que isto tem a ver com a dinâmica de antecipar-a-si-mesmo?

${ }^{28} \mathrm{ST} \S 31$, p. 204. 
A presença já está sempre 'além de si mesma', não como atitude frente aos entes que ela mesma não é, mas como ser para o poderser que ela mesma é. Designamos a estrutura ontológica essencial do 'estar em jogo' como o anteceder-a-si-mesmo da presença. ${ }^{29}$

O ser humano não mora num além "exterior", ou num estado "interior", superior aos demais entes (plantas, animais, coisas, "idéias"). Sendo sempre num aqui e agora, o ser humano é igualmente transcendente, à medida que, sendo propriamente a partir da possibilidade antecipada da morte, nunca se direciona exclusivamente para as coisas, mas, primariamente, para o seu poder-ser, para seu modo de ser abertura para atividades. Talvez possamos visualizar este poder-ser no "como" se faz e não no "que" é feito. Toda atividade vem a ser a partir da possibilidade. Em seu esforço de compreender sua própria morte, o ser humano a descobre antecipadamente como possibilidade privilegiada, pois da sua não realização dependem e se compreendem todas as outras possibilidades. E, a partir desta compreensão antecipada, o ser humano descobre a possibilidade, o ser para o seu poder-ser mais próprio, como o seu mais estranho sustento. Um sustento sem "substância".

O ente privilegiado vem antes, não numa hierarquia de entes simplesmente dados onde o ser humano ocuparia uma primazia, mas porque, antes de tudo, ele está lançado para o angustiante espaço aberto de seu ser: para possibilidades. Este poder-ser nunca sabe "positivamente" como será esta ou aquela possibilidade de fato. Sua pré-visão incorpora tão somente o destino do ser efetivandose nos limites de um espaço aberto de possibilidades. Pré-visão de um destino surpreendente! Cada possibilidade lhe foi inteiramente dada como sua responsabilidade. A compreensão antecipada deste poder-ser não equivale a um conjunto de conhecimentos

${ }^{29}$ ST $\$ 41$, p. $258-259$.

Educ. e Filos. Uberlândia, v. 23, n 45, p. 229-258, jan./jun. 2009. 
que antecedam determinada atividade. Ela, antes, nasce e morre a partir da e na unidade finita do ser-no-mundo. Antecipadamente já sempre encontramos um ser aberto para possibilidades, ou, que o ser humano nunca se esgota ou se esgotou, ou se esgotará, nesta ou naquela possibilidade de fato.

Em se ocupando com as coisas e com os outros, cada ser humano está a se fazer, a construir ininterruptamente seu ser numa sucessão infinita de formas. Existirá, talvez, algum ser, pronto e acabado, herdado a cada um? Segundo nossa interpretação, cada um deve se haver com seu próprio ser, por ele se responsabilizando. Como? Fazendo, construindo-se a partir de seus mais diversos afazeres. $\mathrm{O}$ ser humano, em se exteriorizando, sob as mais diversas formas, já sempre se antecipou a si mesmo, no sentido de ser possibilidade de concretização. Destarte, ele não pode deixar de, a cada vez, ter de decidir por esta ou aquela ou ainda por uma outra possibilidade que se descortina, não precisando ser sempre e continuamente sob uma determinação.

De imediato, encontramos o ser humano submetido a alguma forma histórica, e tentado a considerar o que já foi realizado como a expressão máxima. Ele desdenha, assim, que o máximo não é, simplesmente, o que foi, mas o que virá. Faz-se necessário, então, um olhar que descubra em toda realização uma certa sedimentação do poder-ser. Nenhum ser humano pode substituir o outro na tarefa de ter que assumir este poder-ser em suas atividades. O ser humano, quer o perceba ou não, tem a cada vez que escolher frente à possibilidade de propriedade ou impropriedade sempre abertas. Afinal, se apenas houvesse uma possibilidade, tratar-se-ia de necessidade e não haveria, igualmente, escolha alguma. No entanto, nada está meramente dado de antemão ao ser humano, a não ser, se podemos dizer assim, o seu ser como poder-ser. Por certo, isto não significa que o ser humano está no "nada" ou vive um "nada". Viver um "nada" deve ser ainda existencialmente concebido como uma possibilidade efetiva, um relacionamento mundano possível.

Educ. e Filos. Uberlândia, v. 23, n 45, p. 229-258, jan./jun. 2009. 


\section{Conclusão: a experiência do tempo na existência}

O ser humano, em seu modo de ser antecipado, acena, a cada vez, para a temporalidade de sua consistência. Sendo, ele está a caminho, à medida que atende ao seu modo de ser como uma dinâmica infinita de realização. Em sendo, o porvir torna-se presente. E, sendo, o ser humano também atende a seu inteiro "passado", à medida que se compreende como um ente que nunca foi "inteiramente" realizado para todo o sempre. Neste sentido, tanto o que será quanto o que foi, encontram um ponto de correspondência: a atividade efetiva. A existência contínua de uma certa "incompletude" mantém em aberto o modo de ser de projeto que pertence ao ser humano. Trata-se de uma afirmação que deve ser ontologicamente compreendida: ela não indica nunca uma cadeia passada de repetições que previamente mantivesse o ser humano presente atado às correntes de todo já feito e realizado, oprimindo-o no momento atual ao retirar-lhe toda chance de encontro com o diverso e maravilhoso, com o sonho e com o futuro, pois tudo já teria encontrado lugar na história. Então, em relação ao fluxo do tempo, só restaria o lamento de uma criatura que já não se moveria devido ao peso de um passado. Mas, se por um lado, o ser humano sempre se concretiza num determinado modo de ser, por outro, ele sempre se abre para ser, para fazer-se. Se este aspecto não lhe pertencesse ele não se renovaria, não sucumbiria, não se perderia, e também não se encontraria.

A temporalidade frisada não é aquela que pode ser calculada ou delimitada, seguindo o modelo do relógio que marca e diz o tempo para tudo e para todos, que compreende o tempo como uma infinita repetição do tempo uniforme e sempre igual, onde um tempo delimitado, um espaço de tempo, é sempre igual a todo outro tempo. Também não é aquela temporalidade subjetiva, como um sentimento ou uma intuição pessoal orientadoras de nossas escolhas. Nesse caso, apesar de não haver aquela dissecação temporal como o faz o relógio, há ainda o bisturi subjetivo que determina, a cada vez, um 
tempo certo ou errado, longo ou curto, por exemplo, dizendo que pertence ao "interior" de cada um. A experiência do tempo, distinta de sua apreensão ora mais "objetiva" ou "subjetiva", é chamada de temporalidade. Esta reside na experiência da antecipação, prévia a toda demarcação temporal, acenando para a vivência de estar simplesmente num jogo de "abertura" para... determinações. E ela se dá à nossa compreensão, de fato, quando a experiência da possibilidade se delineia como o ambiente essencialmente humano de ser. Seu tempo é o tempo de ser, a abertura ou o poder-ser já acenado para nossa compreensão e liberado no ser-para-a-morte. Trata-se do futuro como o que está a caminho, como o que virá, como o possível livre e aberto que sempre já se doou ao ser humano. Nunca como um tempo futuro em oposição a um tempo presente e a um tempo passado.

A temporalidade, antecipadamente, libera a possibilidade de todo contar, por exemplo. Posso determinar uma quantidade de entes a partir da possibilidade já sempre aberta de reuni-los num conjunto e de dividi-los ou subdividi-los a partir do mesmo conjunto. Antecedendo-se a si mesmo, o ser humano apreende seu poder-ser como um tempo libertador das ilusões impessoais e liberador para novas possibilidades de ação. Em todo lidar e todo conviver, o ser humano já se posicionou (ou foi posicionado por seu próprio modo de ser) numa abertura mundana, disposta e compreensiva. Como é possível lidar de um jeito, se a possibilidade de lidar já não tivesse sido acessível? Como é possível conviver em determinada relação com os outros, se esta possibilidade de convivência já não tivesse se tornado acessível em seu ser?

De certa forma, anteceder a si mesmo é movimento de transcendência. Mas não no sentido de buscar um mundo além do sensível, um supra-sensível. "Pré" e "trans" (presença) apontam para um comportamento essencial que perpassa toda efetivação. Em seu "da" (Dasein), ou seu "ser-aí", indica-se que o ser humano é sempre mais do que é, porque já sempre se compreendeu como prévio a 
todo ser, e por isso, sempre já ultrapassou toda realidade rumo à possibilidade, ao "mais" de si mesmo. Transcendendo, uma nova realidade é sempre assumida pelo próprio ser humano como sua. Cada desvio é também seu. O ser humano é e está comprometido com a existência, que é sua existência. Ali é seu lugar de perdição e salvação. Tanto se comprometendo claramente com sua existência ou sendo por ela conduzido, o que é carregado na existência é o próprio modo de ser do humano. A existência é seu peso intransferível. Ali seu ser está em jogo a cada vez. Jogando, sendo, o ser humano se compromete consigo mesmo de determinado modo. Se nós só podemos pensar com nossos próprios pensamentos, mesmo quando estes foram como que, copiados, de outros, em nós eles serão nossos de alguma forma, e nós nos entenderemos a partir destes limites. $\mathrm{O}$ que ocorre é que, em geral, esquecemos o aspecto transcendente, refugiando-nos na "evidência" do imanente, ignorando, assim, o caráter de ultrapassamento que ocorre em toda relação mundana. Esquecemos, então, a imbricação entre imanência e transcendência. Em cada situação determinada espaço-temporalmente, é o que está fora de toda situação e permanece indeterminado que transparece antecipadamente conferindo, por exemplo, sentido e limite à atividade. Percebemos que a existência não é um "quê" esparramado. Mas também percebemos que, antecipadamente, lhe pertence a invenção, a surpresa, o inesperado, a estranheza, o abissal. Do contrário, a existência não seria o projeto para o qual estamos lançados desde sempre, um projeto que é sempre realização de um futuro e, neste sentido, do imprevisto.

\section{Referências}

ARENDT, Hannah. A condição humana. Rio de Janeiro: Forense Universitária, 1993, p. 190, 348p.

HEIDEGGER, Martin. Ser e tempo. Trad. Revisada de Márcia de Sá 
Cavalcante Schuback. Petrópolis: ed. Vozes; Bragança Paulista: Ed. Universitária São Francisco, 2006, 598p.

. Carta sobre o humanismo. In: Conferências e escritos filosóficos. Col. Os Pensadores. São Paulo: Ed. Abril Cultural, 1983, $304 \mathrm{p}$.

- Introdução à metafísica, Rio de Janeiro: ed. Tempo brasileiro, 1969, 227p.

HUSSERL, Edmund. A crise da humanidade européia e a filosofia. Porto Alegre : EDIPUCRS, 2002, 96p.

ORTEGA Y GASSET, José. O homem e a gente. RJ: Ed. Livro Iberoamericano ltda, 1960, 304p.

- A rebelião das massas. Rio de Janeiro: Ed. Livro iberoamericano ltda, 1962, 345p.

PISETTA, Écio Elvis. Delimitação da análise existencial da morte. In: Revista Educação e Filosofia, v. 20, n. 40, julho-dezembro 2006, p. 81-109.

Data de Registro 06/06/08

Data de Aceite 15/09/08 